\title{
Temporal variation in seismic moment release rate of slow slips inferred from deep low-frequency tremors in the Nankai subduction zone
}

\author{
Yoko Kono ${ }^{1}$, Keita Nakamoto ${ }^{2}$ and Yoshihiro Hiramatsu ${ }^{3^{*}}$ (1)
}

\begin{abstract}
We examined seismic moment release rates as estimated from deep low-frequency tremors at episodic tremor and slip (ETS) zones on the plate interface in the Nankai subduction zone. Excluding periods with long-term slow slip events, we observe no clear temporal variation in the seismic moment release rate in the Tokai, the northern Kii, or Shikoku regions. We also find no variation in the seismic moment release rate related to the 2011 Tohoku earthquake in the southern or central Kii region. These findings imply that the 2011 Tohoku earthquake has not affected slow slip activities in the Nankai subduction zone. For the southern and central Kii regions, a long-term decrease in the seismic moment release rate with time is apparent, irrespective of the occurrence of the 2011 Tohoku earthquake, suggesting that frictional properties on slip planes at the ETS zone on the plate interface have varied over time.
\end{abstract}

Keywords: Episodic tremor and slip, Plate interface, Pore fluid pressure, Slip plane, The 2011 Tohoku earthquake

\section{Introduction}

Slow earthquakes such as deep low-frequency tremors, very low-frequency earthquakes, and long-term and short-term slow slip events (SSEs) have been found in many subduction zones worldwide (e.g., Obara and Kato 2016). Slow earthquakes, designated as episodic tremor and slip (ETS) (Rogers and Dragert 2003), usually accompany tremors. The ETS zones are located at deeper extensions of the source area of great earthquakes in subduction zones. Consequently, investigating features of slow slips is important to elucidate the generation process of great earthquakes.

The 2011 off the Pacific coast of Tohoku earthquake (Mw 9.0), hereinafter designated as the 2011 Tohoku

\footnotetext{
*Correspondence: yoshizo@staff.kanazawa-u.ac.jp

${ }^{3}$ School of Geosciences and Civil Engineering, College of Science and Engineering, Kanazawa University, Kakuma, Kanazawa, Ishikawa 920-1192, Japan

Full list of author information is available at the end of the article
}

earthquake, has modified the stress and strain fields in Japanese Islands not only through coseismic, but also through postseismic crustal deformations. This modification might affect the crustal dynamics of the Japanese Islands. In northeastern Japan, a clear increase of seismicity and a change of focal mechanisms have been observed (e.g., Yoshida et al. 2012). The 2011 Tohoku earthquake has also affected the activity of slow slips near the source region. After the 2011 Tohoku earthquake, shortening of the recurrence interval of slow slip events off the coast of the Boso Peninsula in Japan has been observed (Hirose et al. 2012; Ozawa 2014). Hirose et al. (2012) and Ozawa (2014) inferred that the shortening of the recurrence interval is attributable to the change in Coulomb failure stress on the fault plane caused by coseismic slip and afterslip of the 2011 Tohoku earthquake.

In the Nankai subduction zone, the average slip rates at the ETS zone have been estimated (Hirose et al. 2010b; Ishida et al. 2013; Daiku et al. 2018) based on an empirical relation between the apparent moment of tremors and 
the seismic moment of short-term SSEs (Hiramatsu et al. 2008). It is particularly interesting that the estimated slip rate is coincident with the difference between the convergence rate of the Philippine Sea plate and the slip deficit rate at the ETS zone. A recent study of the spatiotemporal distributions of the interplate couplings and the count rate of tremors in the Shikoku region has indicated that the tremor count rate is useful as a proxy for monitoring small fluctuations in interplate coupling at the ETS zone (Ochi and Takeda 2018). Therefore, examining the variation in slow slip activity in the Nankai subduction zone through tremors is interesting, but no marked change in slow slip activity has been observed there geodetically based on data obtained before and after the 2011 Tohoku earthquake.

Moreover, reports of some simulation studies have described activation of slow slips before a great earthquake in a subduction zone (e.g., Matsuzawa et al. 2010). Detecting such activation requires clarification of the degree of fluctuation in the slip rate in the ETS zone. Tremor data have now been collected for more than 15 years in the Nankai subduction zone. It is therefore suitable to examine not only the average slip rate, but also the fluctuation in the slip rate, i.e., fluctuation in the seismic moment release rate through tremors occurring in the ETS zone. For the Nankai subduction zone, Daiku et al. (2018) reported temporal variation in the cumulative seismic moment of slow slips estimated from tremors during 11 years. Some deviations from a constant rate in the cumulative seismic moment of slow slips might exist, especially for the central-southern Kii and the Tokai regions. Nevertheless, Daiku et al. (2018) devoted no attention to the deviations. Actually, detailed analysis of temporal variation is necessary to examine the deviations. Furthermore, the period analyzed by Daiku et al. (2018) is insufficient to reveal differences in the seismic moment release rate before and after the 2011 Tohoku earthquake for its long duration of postseismic deformation.

For this study, we investigated the temporal variation in the seismic moment release rate through the activity of tremors in the Nankai subduction zone. We discuss not only the 2011 Tohoku earthquake effects on the seismic moment release rate, but also long-term variation in the seismic moment release rate.

\section{Data}

We divided the Nankai subduction zone into seven regions according to tremor activity: Tokai; northern, central, and southern Kii Peninsula; and eastern, central, and western Shikoku (Hirose et al. 2010b; Ishida et al. 2013; Daiku et al. 2018) (Fig. 1). For this study, to estimate the seismic moment release rate at the ETS zone, we used the apparent moment as the tremor size and the conversion rate, which is a coefficient to convert the apparent moment of an episode of tremors to the seismic moment of a corresponding slow slip (Hiramatsu et al. 2008). Daiku et al. (2018) reported the

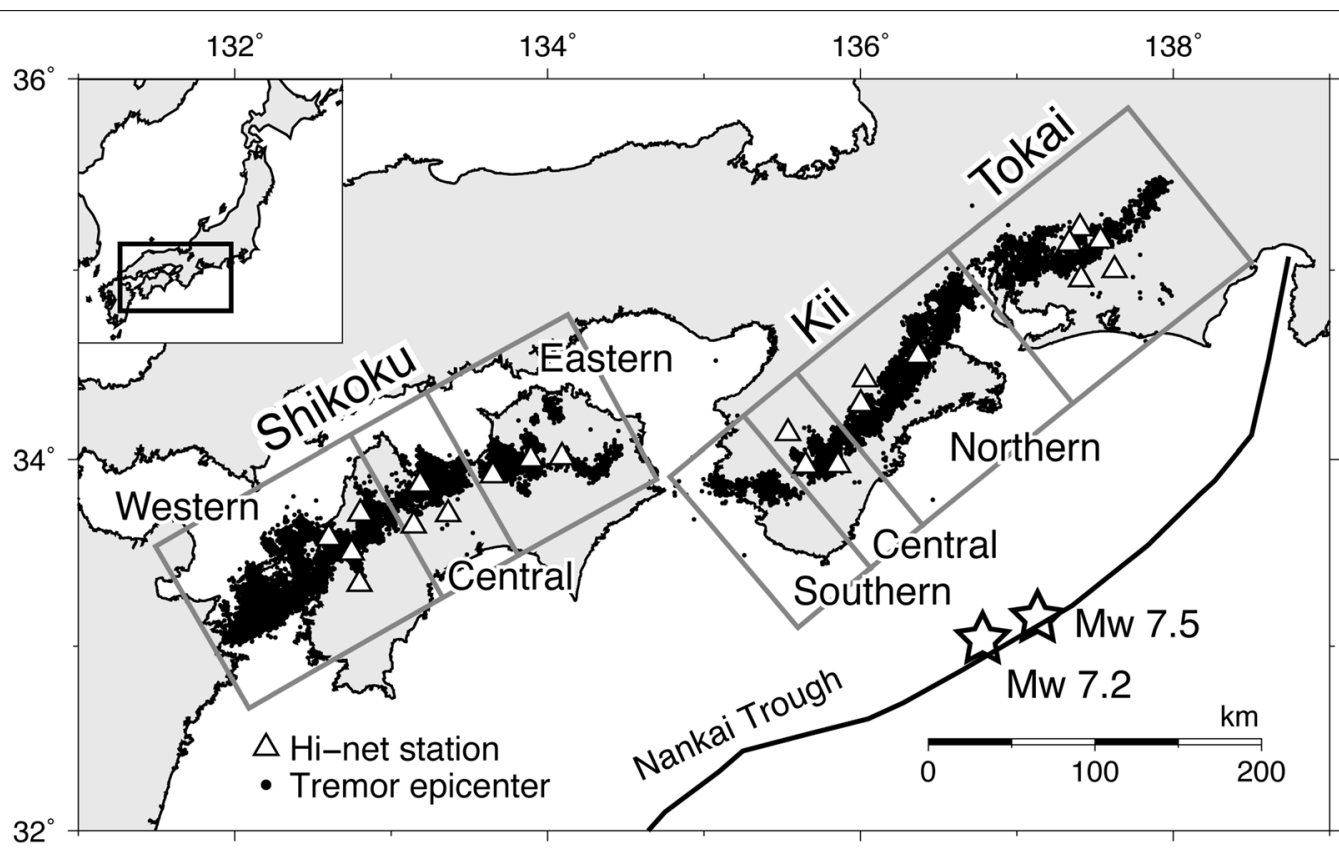

Fig. 1 Distributions of the epicenters of DLF tremors (dots) (Obara et al. 2010) and the analyzed regions (rectangles). Triangles are Hi-net stations used for this study. Stars denote the epicenters of two intra-slab earthquakes off the Kii Peninsula in 2004 
conversion factors for all regions. We applied their conversion factors for this study. We also used the apparent moment of tremors during April 2002-July 2013, as estimated by Daiku et al. (2018).

For this study, we extended the analytical period to March 2001-April 2016. To estimate the apparent moment during March 2001-March 2002 and during August 2013-April 2016, we referred to hypocenter catalogs of tremors of the hybrid method (Maeda and Obara 2009) for visual checking of the waveform data and those of the hybrid clustering method for the tremor location (Obara et al. 2010). The waveform data analyzed for this study were the vertical component of the velocity waveform recorded at Hi-net stations operated by the National Research Institute for Earth Science and Disaster Resilience (NIED) (Fig. 1). Stations used for this study are the same as those used for a study reported by Daiku et al. (2018) (Fig. 1).

\section{Method}

The procedure used to estimate the apparent moment is the same as that reported by Daiku et al. (2018). We calculated the time integral of the envelope of bandpass filtered $(2-10 \mathrm{~Hz})$ velocity waveforms of tremors with corrections of the geometrical spreading and the inelastic attenuation $(Q=184)$ as the apparent moment (details presented by Daiku et al. 2018). By applying the conversion factor reported by Daiku et al. (2018), we calculated the seismic moment from the apparent moment.

We estimated the seismic moment release rate from the cumulative seismic moment during 1 year in each region. To emphasize the effects of the 2011 Tohoku earthquake on slow slips at the ETS zone, before the 2011 Tohoku earthquake, the analyzed period of 1 year starts on March 11 and ends on March 10 of the subsequent year. After the 2011 Tohoku earthquake, we set those to April 11 and on April 10 of the subsequent year because the aftershock activity immediately after the 2011 Tohoku earthquake might reduce the detection capabilities of tremors in the Nankai subduction zone.

The observed tremor data are likely to include fluctuations of tremor activity in nature, although we do not know the true distribution of the fluctuation. To reduce effects of the fluctuation on estimation of the cumulative seismic moment in 1 year, we applied the nonparametric bootstrap method. The bootstrap sample size is the same as the observed size for every year in each region. We calculated the average and the $95 \%$ confidence range, as estimated using percentile method, of the cumulative seismic moment in 1 year, which is the seismic moment release rate, from 2000 bootstrap estimations.

\section{Results and discussion}

Relation between the seismic moment release rate, long-term SSEs, and the $\mathbf{2 0 1 1}$ Tohoku earthquake

Figure 2 portrays temporal variations in the cumulative seismic moment for the respective regions. Results show sharp changes in slope of the cumulative seismic moment during 2002-2005 and 2013-2016 in Tokai and during 2003-mid-2004, 2010, and 2014-2015 in the western Shikoku regions. These increases correspond to long-term SSEs in Tokai (Ozawa et al. 2016) and in the Bungo channel (Hirose and Obara 2005, 2010; Ozawa et al. 2013; Ozawa 2017). The cumulative seismic moment in the southern Kii region also shows a weak change in slope after mid-2014. This change apparently corresponds to a long-term SSE in the Kii channel (GSI 2016). Takagi et al. (2016) reported longterm SSEs in western-to-central Shikoku during early 2004-early 2006 and early 2011-mid-2013. These SSEs might enhance tremor activities in western and central Shikoku. However, no change in the slope of the cumulative seismic moment can be recognized in the corresponding periods (Fig. 2). Therefore, we infer that the long-term SSEs reported by Takagi et al. (2016) do not affect tremor activity in the western and central Shikoku regions. Their periods are not shown in Figs. 2 and 3 . It is interesting that no slope of cumulative seismic moment for any region in the Nankai subduction zone shows a clear change accompanying the 2011 Tohoku earthquake.

Figure 3 presents temporal variations in the seismic moment release rate at the ETS zone in the respective regions. In Fig. 3, we show the average long-term slip rate and its $95 \%$ confidence range, which are estimated in periods with no long-term SSEs, as reported by Daiku et al. $(2018,2019)$. It is noteworthy that, for the northern Kii region, the average long-term slip rate and its $95 \%$ confidence range are corrected, respectively, to 4.0 and 3.3-4.9 $\left(\times 10^{18} \mathrm{Nm} /\right.$ year $)$ by Daiku et al. (2019). Except for results calculated for the time around the periods with long-term SSEs, the seismic moment release rate is almost constant in the Tokai, the northern Kii, and the eastern, central, and western Shikoku regions, although scattering exists around the average slip rate. In the southern Kii region, the seismic moment release rate apparently decreases after the 2011 Tohoku earthquake. However, such a decrease can be found irrespective of the 2011 Tohoku earthquake in the southern Kii region. In other words, considering that an increase around 2015 might be induced by a long-term SSE in the Kii channel, the seismic moment release rate in the southern Kii region decreases gradually with time. A long-term decrease in the seismic moment release rate might be found in the central Kii region as well. 


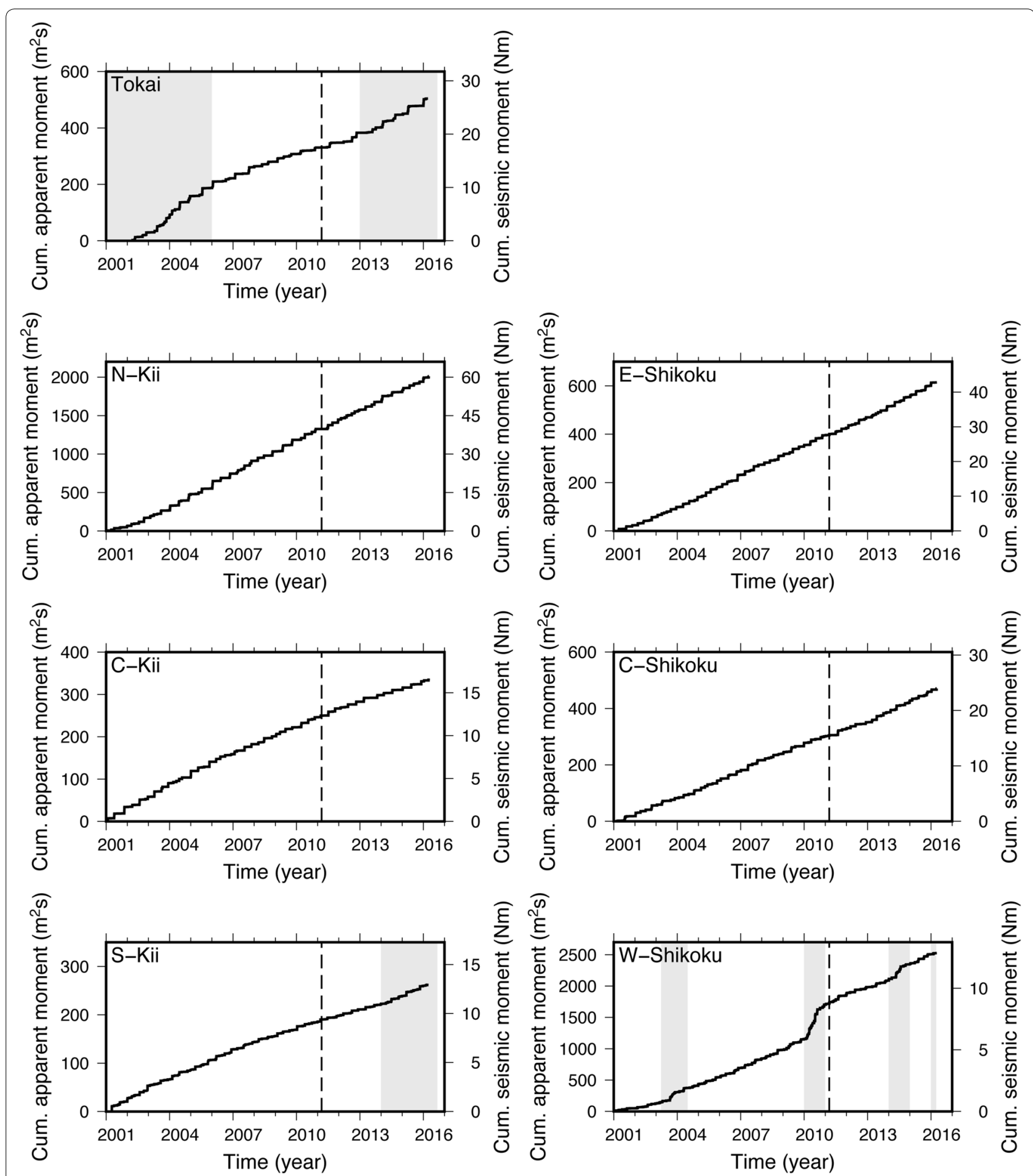

Fig. 2 Temporal variation in cumulative apparent moment (left axis) and in the cumulative seismic moment (right axis) estimated from DLF tremors (black line) in each region. Gray hatched zones show the period of long-term SSEs in the Tokai region (Ozawa et al. 2016), in the Kii channel (GSI 2016), and in the Bungo channel (Hirose and Obara 2005; Hirose et al. 2010a; Ozawa et al. 2013; Ozawa 2017). A vertical dashed line represents the occurrence of the 2011 Tohoku earthquake 
(See figure on next page.)

Fig. 3 Temporal variation in the apparent moment rate (left axis) and seismic moment release rate (right axis) in respective regions (solid circles). The $95 \%$ confidence range is estimated using the nonparametric bootstrap method. The horizontal solid line, dashed line, and gray zone, respectively, represent the average slip rate reported by Daiku et al. $(2018,2019)$, its extrapolation/interpolation, and its $95 \%$ confidence range. A vertical dashed line represents the origin time of the 2011 Tohoku earthquake. Horizontal gray bars show the period of long-term SSEs in the Tokai region (Ozawa et al. 2016), in the Kii channel (GSI 2016), and in the Bungo channel (Hirose and Obara 2005; Hirose et al. 2010a; Ozawa et al. 2013; Ozawa 2017)

These results show no clear difference in the seismic moment release rate before and after the 2011 Tohoku earthquake. We therefore consider that the 2011 Tohoku earthquake did not affect the seismic moment release rate of slow slips at the ETS zone in the Nankai subduction zone. The coseismic and postseismic crustal deformations of the 2011 Tohoku earthquake are characterized by a long-wavelength deformation pattern over the Japanese Islands. Therefore, less spatial variation exists in the displacement field and in the strain field, causing less effective variation in stress at the ETS zone in the Nankai subduction zone. Excluding dynamic triggering after the passage of large seismic waves, this result coincides with the lack of a marked increase of seismicity after the 2011 Tohoku earthquake in areas far from the source area of the 2011 Tohoku earthquake. The lesser variation in seismicity in areas far from the source area can be interpreted as small Coulomb stress changes induced by the 2011 Tohoku earthquake (e.g., Toda et al. 2011). Large earthquakes often modify the subsequent activities of tremors and short-term SSEs after earthquakes, e.g., off the Boso Peninsula, Japan (Hirose et al. 2012; Ozawa 2014), on the southern San Andreas fault (Tymofyeyeva et al. 2019), and on the Hikurangi subduction zone, New Zealand (Jiang et al. 2018). Nevertheless, no report describes decade-scale variation in tremors or short-term SSEs activities caused by large earthquakes.

\section{Possible causes of a long-term decrease in seismic moment release rate}

Some possible causes might explain the observed longterm decreases in the seismic moment release rate in the central and southern Kii regions when one assumes that the observed decreases are not a decade-scale fluctuation. Variation in tremor detection might result from changes in the seismic network, seismometer, and procedures for processing tremor detection. This possibility can be discounted as unlikely because no decade-scale change has been identified for these factors.

Tectonic events and slow slip events around the Kii Peninsula might induce variation in tremor activities in the central and southern Kii regions. Two large intra-slab earthquakes of Mw 7.2 and Mw 7.5 occurred on September 5, 2004 southeast of the Kii Peninsula (Fig. 1). These earthquakes triggered coseismically very low-frequency earthquakes in the accretionary wedge near the source regions (Obara and Ito 2005). However, for the central and southern Kii regions, no report has described clear changes in tremor activities accompanying these events. Finding remarkable change in the cumulative seismic moment and seismic moment release rate attributable to these events is difficult (Figs. 2 and 3). The afterslip of these earthquakes has been detected geodetically. Suito and Ozawa (2009) estimated the time constant of the postseismic deformation caused by the afterslip as about 2 months, suggesting that postseismic deformation is not a cause of the long-term variation in the seismic moment release rate. The effect of the viscoelastic relaxation might be another cause of variation in tremor activities because the viscoelastic model can reproduce most of the southward motion observed after these earthquakes (Suito 2017). However, geodetic analyses including the viscoelastic effect detected no long-term slow slips beneath the Kii Peninsula (Suito 2017). Therefore, we infer that the 2004 intra-slab earthquakes off the Kii Peninsula are not a cause of the long-term decreases in seismic moment release rate. Long-term SSEs in the Tokai region, Kii Channel and the Shikoku regions might affect tremor activities in the Kii regions. As presented in Figs. 2 and 3, the slow slip events in Tokai and Shikoku do not markedly modify the seismic moment release rate in the central and southern Kii regions. The long-term slow slip event in the Kii Channel around 2015 seems to modify the seismic moment release rate in the southern Kii region (Fig. 3), although the sense of the variation is opposite to the long-term decrease. Usually, long-term slow slips enhance tremor activity. Therefore, it is difficult to interpret the observed long-term decrease as the effect of long-term slow slips, even if long-term SSEs in and around the Kii Peninsula are missing.

The long-term average slip rate is approximately coincident with the difference between the convergence rate and the slip deficit rate of the subducting Philippine Sea plate (Hirose et al. 2010b; Ishida et al. 2013; Daiku et al. 2018). Assuming a constant conversion factor, two possibilities might explain the long-term decrease in the seismic moment release rate in the central and southern Kii regions: a decrease in the convergence rate of the Philippine Sea plate and an increase in the slip deficit rate at the ETS zone. The first possibility must be discounted. 

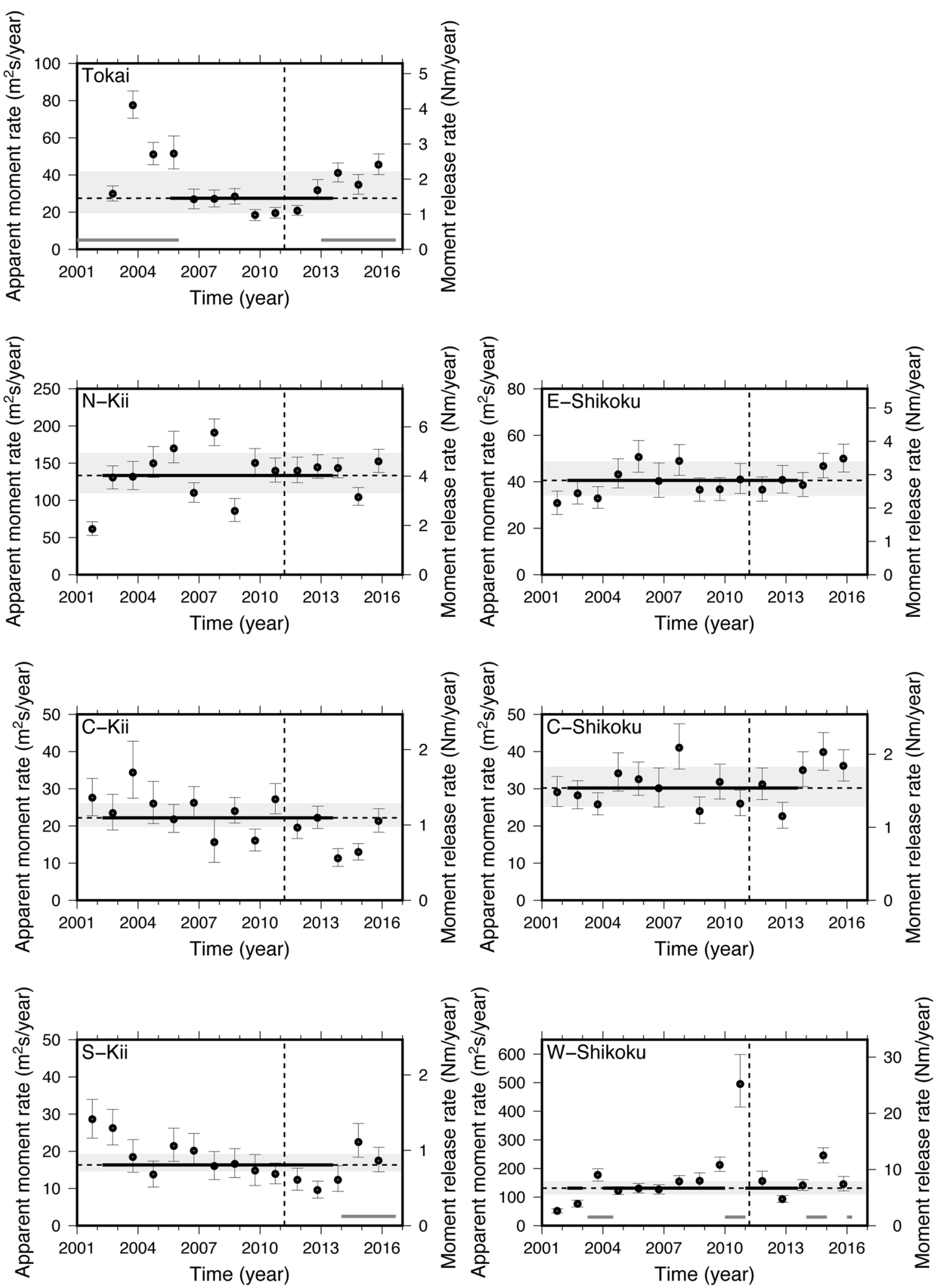
It is unlikely because variation in the seismic moment release rate would be observed in neighboring regions if a decrease of the convergence rate were to occur. The second possibility appears more plausible because local variation in the frictional properties on slip planes at the ETS zone might change the slip deficit rate. Daiku et al. (2018) discussed a cause of heterogeneous spatial distribution of the excitation efficiency of tremors for short-term SSEs along the Nankai subduction zone based on the mineral assemblages of serpentinite in the mantle wedge reported by Mizukami et al. (2014). They suggested that heterogeneity of the pore fluid pressure on the plate interface, induced by the phase transition of antigorite serpentinite, strongly affects the heterogeneous distribution of the excitation efficiency. In other words, tremors are easily excited by stress perturbation accompanied by a shortterm SSE under high pore fluid pressure. High pore fluid pressure can reduce the slip deficit rate because SSEs tend to occur easily under high pore fluid pressure. If this relation were applied to a temporal variation in the slip deficit rate, then a long-term increase in the slip deficit rate could result from a long-term decrease in the pore fluid pressure.

However, a complicated problem then confronts us. Variation of the pore fluid pressure might cause variation in the conversion factor as well: a break of a constant conversion factor. The decrease in the pore fluid pressure corresponds to a decrease in the excitation efficiency and to an increase in the conversion factor (Daiku et al. 2018). An apparent decrease in the seismic moment release rate would be induced by an increase in the conversion factor because we estimated the seismic moment from the apparent moment with a constant conversion factor.

Figure 4 presents temporal variation in the conversion factor, as estimated for each short-term SSE in the respective regions: central-western Shikoku, eastern Shikoku, central-southern Kii, and the northern Kii and Tokai regions. We used SSEs reported by Sekine et al. (2010) and data from Reports of the Coordinating Committee for Earthquake Prediction (CCEP), Japan (https ://cais.gsi.go.jp/YOCHIREN/report.e.html). Reports of CCEP include two datasets of SSEs: one reported by NIED and the other by the National Institute of Advanced Industrial Science and Technology (AIST) and NIED. For SSEs in the Shikoku, Tokai, and the northern Kii regions, we used data reported by Sekine et al. (2010) and Reports of CCEP published by NIED, which were estimated from tilt-meter records. For SSEs in the central-southern Kii regions, we used the data of Reports of CCEP published by AIST and NIED, which were estimated from strain-meter and tilt-meter records. The estimated size of SSEs depends on assumptions used for the analyses, resulting in low reliability of the estimated size for some SSEs. Consequently, conversion factors show large scatter caused by relatively large uncertainties of the SSE sizes.

For western-central and eastern Shikoku, and the northern Kii and Tokai regions, it is difficult to identify a systematic variation in the conversion factor with time (Fig. 4). The two largest data for the western-central Shikoku regions might be caused by large uncertainties of the estimated size of SSEs. Therefore, we infer that the conversion factors in these regions are constant rather than representing clear temporal variation. The constant conversion factors found for Shikoku are consistent with results reported by Ochi and Takeda (2018). They reported that fluctuation in the coupling rate correlated well with the tremor count rates at the ETS zone in Shikoku during 2007-2016. Except for the period with long-term SSEs, the tremor count rate is almost constant in Shikoku, meaning that interplate coupling is almost constant, and indicating an almost constant slip deficit rate and conversion factor. For the central-southern Kii regions, no SSEs estimated from strain-meter and/ or tilt-meter records are available before 2012. However, considering the wide divergence of the conversion factors, together with data from four SSEs estimated from Global Navigation Satellite System data (Nishimura et al. 2013), we infer a low possibility of long-term variation in the conversion factor. Large uncertainties of the estimated size of SSEs might result in the two largest data for the central-southern Kii regions. Welch's $t$ test supports no statistically significant difference in the mean of the conversion factor before and after the 2011 Tohoku earthquake.

In any case, a long-term decrease in the pore fluid pressure might play an important role in the observed longterm decrease in the seismic moment release rate in the central and southern Kii regions. We, therefore, suggest that the observed long-term variation in seismic moment release rate reflects long-term variation in frictional properties, which might be influenced strongly by pore fluid pressure on slip planes at the ETS zone on the plate interface.

\section{Conclusions}

Seismic moment release rates of slow slips at ETS zones were investigated for seven regions in the Nankai subduction zone using data of 2001-2016. The seismic moment release rates estimated from tremors were almost constant, except for periods of long-term SSEs in the Tokai, northern Kii, and eastern, central and western Shikoku regions. Results show that no variation exists in the seismic moment release rate accompanied by the 2011 Tohoku earthquake in the seven regions. No variation has resulted from the long-wavelength crustal deformation 

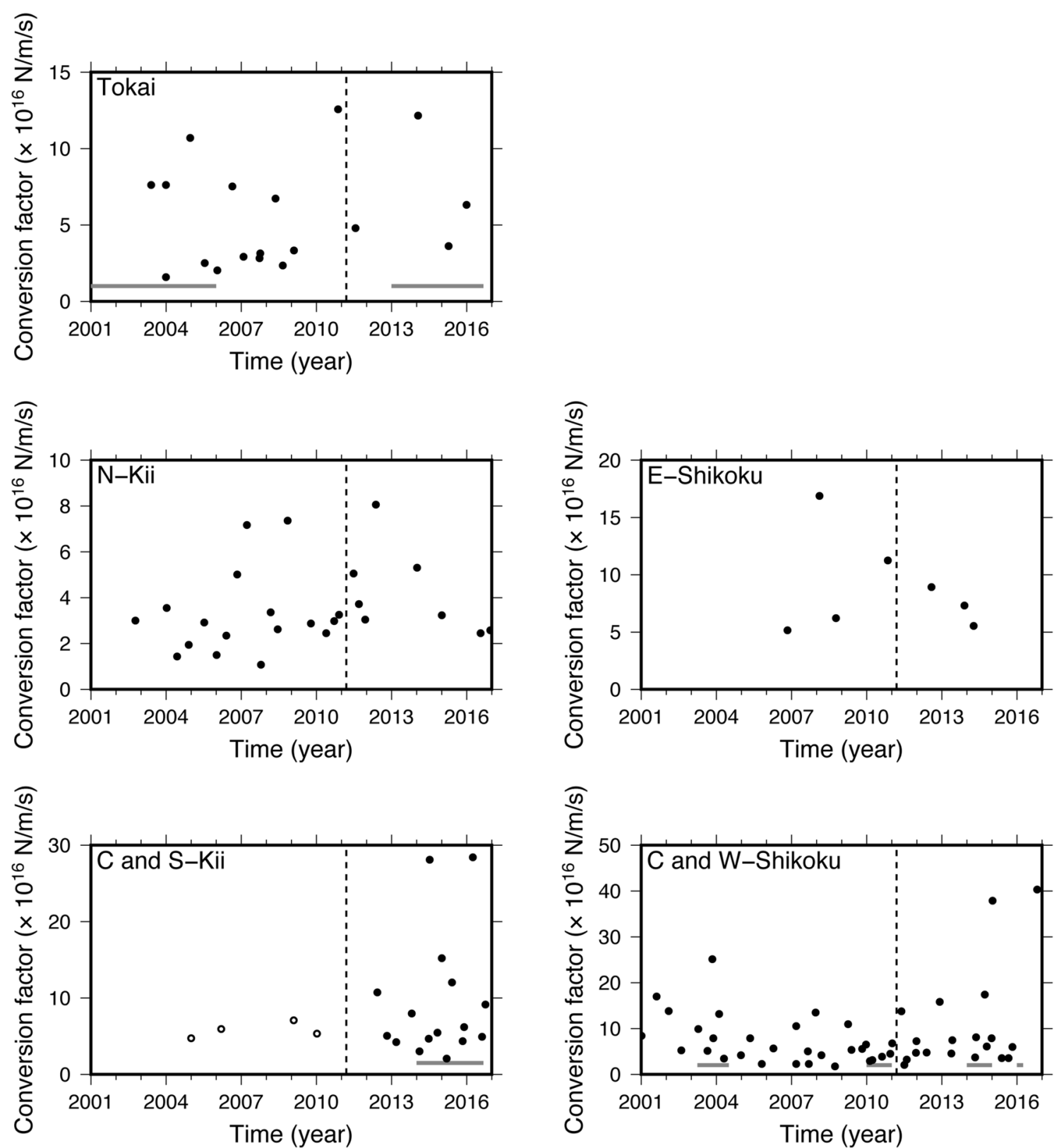

Fig. 4 Temporal variation in the conversion factors estimated for each short-term SSE in respective regions. Solid circles show data calculated from SSEs reported by Sekine et al. (2010) and reports of CCEP. Horizontal gray bars are the same as those shown in Fig. 3. Open circles in the central-southern Kii regions (lower-left panel) show data calculated from SSEs reported by Nishimura et al. (2013)

pattern and small Coulomb stress changes induced by the 2011 Tohoku earthquake. In the southern Kii region and in the central Kii region, long-term decreases were found in the seismic moment release rates. The decreases might be attributable to long-term variation in frictional properties on slip planes at the ETS zone. Pore fluid pressure might play an important role in the long-term variation of frictional properties on slip planes in these regions.
Abbreviations

SSE: Slow slip event; ETS: Episodic tremor and slip.

\section{Acknowledgements}

We used R (R Core Team 2019) and Generic Mapping Tool (Wessel and Smith 1998) software for this study. The waveform data were provided by the National Research Institute for Earth Science and Disaster Resilience. We are grateful to Takaki Iwata for helpful discussion. Constructive comments 
from anonymous reviewers and David Shelly were useful to improve the manuscript.

\section{Authors' contributions}

$\mathrm{YH}$ and $\mathrm{YK}$ designed this study. $\mathrm{YK}, \mathrm{KN}$, and $\mathrm{YH}$ conducted analyses. $\mathrm{YH}$ drafted the manuscript. All authors read and approved the final manuscript.

\section{Funding}

This work was partly supported by Global Science Campus program of Japan Science and Technology Agency (JST).

\section{Availability of data and materials}

All waveform data used for this study were obtained through the website of Hi-net of National Research Institute for Earth Science and Disaster Resilience. All data of short-term SSEs were obtained from Sekine et al. (2010) and from the website of Reports of CCEP.

\section{Competing interests}

The authors declare that they have no competing interests.

\section{Author details}

1 Yokohama Science Frontier High School, Onocho 6, Tsurumi, Yokohama 230-0046, Japan. ${ }^{2}$ Graduate School of Natural Science and Technology, Kanazawa University, Kakuma, Kanazawa, Ishikawa 920-1192, Japan. ${ }^{3}$ School of Geosciences and Civil Engineering, College of Science and Engineering, Kanazawa University, Kakuma, Kanazawa, Ishikawa 920-1192, Japan.

Received: 8 October 2019 Accepted: 22 January 2020

Published online: 03 February 2020

\section{References}

Daiku K, Hiramatsu Y, Matsuzawa T, Mizukami T (2018) Slow slip rate and excitation efficiency of deep low frequency tremors beneath southwest Japan. Tectonophysics 722:314-323

Daiku K, Hiramatsu Y, Matsuzawa T, Mizukami T (2019) Erratum to slow slip rate and excitation efficiency of deep low frequency tremors beneath southwest Japan. Tectonophysics (submitted)

GSI (2016) Crustal movements in the Kinki district, Japan. Coord Commit Eq Pred 95:296

Hiramatsu Y, Watanabe T, Obara K (2008) Deep low-frequency tremors as a proxy for slip monitoring at plate interface. Geophys Res Lett 35:L13304. https:// doi.org/10.1029/2008gl034342

Hirose H, Obara K (2005) Repeating short-and long-term slow slip events with deep tremor activity around the Bungo channel region, southwest Japan. Earth Planets Space. https://doi.org/10.1186/bf03351875

Hirose H, Obara K (2010) Recurrence behavior of short-term slow slip and correlated nonvolcanic tremor episodes in western Shikoku, southwest Japan. J Geophys Res 115:B00A21. https://doi.org/10.1029/2008jb006050

Hirose H, Asano Y, Obara K, Kimura T, Matsuzawa T, Tanaka S, Maeda T (2010a) Slow earthquakes linked along dip in the Nankai subduction zone. Science 330:1502

Hirose T, Hiramatsu Y, Obara K (2010b) Characteristics of short-term slow slip events estimated from deep low-frequency tremors in Shikoku, Japan. J Geophys Res 115:B10304. https://doi.org/10.1029/2010jb007608

Hirose H, Kimura H, Enescu B, Aoi S (2012) Recurrent slow slip event likely hastened by the 2011 Tohoku earthquake. PNAS 109(38):15157-15161. https:// doi.org/10.1073/pnas.1202709109

Ishida R, Hiramatsu Y, Matsuzawa T, Obara K (2013) Average slip rate at the transition zone on the plate interface beneath the Kii Peninsula, Japan, estimated from deep low-frequency tremors. Earth Planets Space 65:1047-1051. https ://doi.org/10.5047/eps.2013.04.003

Jiang Z, Yuan L, Huang D, Zhang L, Hassan A, Yang Z (2018) Spatial-temporal evolution of slow slip movements triggered by the 2016 Mw 7.8 Kaikoura earthquake, New Zealand. Tectonophysics 744:72-81

Maeda T, Obara K (2009) Spatiotemporal distribution of seismic energy radiation from low-frequency tremor in western Shikoku, Japan. J Geophys Res 114:B00A09. https://doi.org/10.1029/2008jb006043

Matsuzawa T, Hirose H, Shibazaki B, Obara K (2010) Modeling short- and longterm slow slip events in the seismic cycles of large subduction earthquakes. J Geophys Res 115:B12301. https://doi.org/10.1029/2010jb007566
Mizukami T, Yokoyama H, Hiramatsu Y, Arai S, Kawahara H, Nagaya T, Wallis SR (2014) Two types of antigorite serpentinite controlling heterogeneous slowslip behaviours of slab-mantle interface. Earth Planet Sci Lett 401:148-158

Nishimura T, Matsuzawa T, Obara K (2013) Detection of short-term slow slip events along the Nankai Trough, southwest Japan, using GNSS data. J Geophys Res 118:3112-3125. https://doi.org/10.1002/jgrb.50222

Obara K, Ito Y (2005) Very low frequency earthquakes excited by the 2004 off the Kii peninsula earthquakes: a dynamic deformation process in the large accretionary prism. Earth Planets Space 57:321-326. https://doi. org/10.1186/BF03352570

Obara K, Kato A (2016) Connecting slow earthquakes to huge earthquakes. Science 353:253-257. https://doi.org/10.1126/science.aaf1512

Obara K, Tanaka S, Maeda T (2010) Depth-dependent activity of nonvolcanic tremor in southwest Japan. Geophys Res Lett 37:L13306. https://doi. org/10.1029/2010gl043679

Ochi T, Takeda N (2018) Relation between the coupling and tremor rates in the transition zone around the Shikoku region. Earth Planets Space 70:114. https ://doi.org/10.1186/s40623-018-0883-8

Ozawa S (2014) Shortening of recurrence interval of Boso slow slip events in Japan. Geophys Res Lett 41:2762-2768. https://doi.org/10.1002/2014gl0600 72

Ozawa S (2017) Long-term slow slip events along the Nankai trough subduction zone after the 2011 Tohoku earthquake in Japan. Earth Planets Space 69:56. https://doi.org/10.1186/s40623-017-0640-4

Ozawa S, Yarai H, Imakiire T, Tobita M (2013) Spatial and temporal evolution of the long-term slow slip in the Bungo Channel, Japan. Earth Planets Space 65:67-73. https://doi.org/10.5047/eps.2012.06.009

Ozawa S, Tobita M, Yarai H (2016) A possible restart of an interplate slow slip adjacent to the Tokai seismic gap in Japan. Earth Planets Space 68:54. https ://doi.org/10.1186/s40623-016-0430-4

R Core Team (2019) R: A language and environment for statistical computing. R Foundation for Statistical Computing, Vienna, Austria. https://www.R-proje ct.org/

Rogers G, Dragert H (2003) Episodic tremor and slip on the Cascadia subduction zone: the chatter of silent slip. Science 300:1942-1943. https://doi. org/10.1126/science.1084783

Sekine S, Hirose H, Obara K (2010) Along-strike variations in short-term slow slip events in the southwest Japan subduction zone. J Geophys Res 115:B00A27. https://doi.org/10.1029/2008jb006059

Suito H (2017) Viscoelastic relaxation caused by the 2004 off the Kii Peninsula earthquake. J Seismol Soc Jpn 70:135-145 (in Japanese with English abstract)

Suito H, Ozawa S (2009) Transient crustal deformation in the Tokai district-the Tokai slow slip event and postseismic deformation caused by the 2004 off southeast Kii Peninsula. J Seismol Soc Jpn 61:113-135 (in Japanese with English abstract)

Takagi R, Obara K, Maeda T (2016) Slow slip event within a gap between tremor and locked zones in the Nankai subduction zone. Geophys Res Lett 43:1066-1074. https://doi.org/10.1002/2015gl066987

Toda S, Lin J, Stein RS (2011) Using the 2011 Mw 9.0 off the Pacific coast of Tohoku Earthquake to test the Coulomb stress triggering hypothesis and to calculate faults brought closer to failure. Earth Planets Space 63:725-730. https://doi.org/10.5047/eps.2011.05.010

Tymofyeyeva E, Fialko Y, Jiang J et al (2019) Slow slip event on the southern San Andreas fault triggered by the 2017 Mw8.2 Chiapas (Mexico) earthquake. J Geophys Res Solid Earth 124:9956-9975. https://doi.org/10.1029/2018j b016765

Wessel P, Smith WHF (1998) New improved version of generic mapping tools re-leased. EOS Trans AGU 79:579

Yoshida K, Hasegawa A, Okada T, linuma T, Ito Y, Asano Y (2012) Stress before and after the 2011 great Tohoku-oki earthquake and induced earthquakes in inland areas of eastern Japan. Geophys Res Lett 39:L03302. https://doi. org/10.1029/2011gl049729

\section{Publisher's Note}

Springer Nature remains neutral with regard to jurisdictional claims in published maps and institutional affiliations. 